\title{
Perinatal factors associated with developmental defects of enamel in primary teeth: a case-control study
}

Patrícia Corrêa-Faria ${ }^{(a)}$

Paulo Antônio Martins-Júnior ${ }^{(a)}$

Raquel Gonçalves Vieira-

Andrade ${ }^{(a)}$

Leandro Silva Marques(b)

Maria Letícia Ramos-Jorge ${ }^{(a)}$

(a) Department of Pediatric Dentistry, School of Dentistry, Univ Federal dos Vales do Jequitinhonha e Mucuri - UFVJM, Diamantina, MG, Brazil.

(b) Department of Orthodontics, School of Dentistry, Univ Federal dos Vales do Jequitinhonha e Mucuri - UFVJM, Diamantina, MG, Brazil.

Declaration of Interests: The authors certify that they have no commercial or associative interest that represents a conflict of interest in connection with the manuscript.

Corresponding Author:

Patrícia Corrêa-Faria

E-mail: patriciafaria.faria09@gmail.com

Submitted: Oct 08, 2012

Accepted for publication: Feb 06, 2013

Last revision: Feb 20, 2013
Abstract: The present study was designed to evaluate associations between developmental defects of enamel (DDE) in the primary dentition and aspects related to mothers and preschoolers in the city of Diamantina, Brazil. A case-control study was carried out involving children aged three to five years. The case group was composed of 104 children with at least one dental surface affected by DDE. The control group comprised 105 children without DDE, matched for gender and age. The diagnosis of enamel defects was performed using the Developmental Defects of Enamel Index. Information was collected through interviews investigating socio-demographic aspects, gestation, birth weight, prematurity and breastfeeding. Simple and multiple regression analyses were performed, providing unadjusted and adjusted prevalence ratios (Poisson regression). DDE were more prevalent among children who had not been breastfed $(\mathrm{PR}=1.57$; 95\% CI: 1.1-2.2) and those whose mothers were under 24 years of age at the birth of the child (PR $=1.41 ; 95 \%$ CI: $1.1-1.9)$. The prevalence of DDE in the primary dentition was higher among children who had not been breastfed and those whose mothers were under 24 years of age at the birth of the child.

Descriptors: Tooth, Deciduous; Dental Enamel Hypoplasia; Dental Enamel.

\section{Introduction}

Developmental defects of enamel (DDE) are defined as disturbances in hard tissue matrices and mineralization occurring during odontogenesis. These defects are classified as either enamel hypoplasia or enamel opacities, based on clinical appearance. ${ }^{1-3}$ Enamel hypoplasia is associated with a reduction in the thickness of the enamel in either a localized or a more widespread area, but the enamel matrix is mineralized normally. ${ }^{1}$ It may manifest clinically in the form of pits and grooves, or else a partial/total lack of surface enamel. ${ }^{1,2}$ In the case of enamel opacities, the matrix is secreted to form a normal thickness, but parts fail to mature or mineralize properly, leaving regions with deficient mineral content, which appear as diffuse or demarcated opacities of yellowish or brown coloration. ${ }^{4}$

The prevalence of DDE in the primary dentition ranges from $24.4 \%$ to $81.3 \%$ in different countries. ${ }^{5,6}$ The etiological factors associated with acquired DDE may act prenatally, perinatally or postnatally, and may 
be either systemic or localized. Studies have demonstrated that premature birth, low birth weight and lack of breastfeeding are the main causes of DDE in primary teeth. ${ }^{7-8}$ Furthermore, enamel defects are related to social aspects, as well as nutritional and systemic problems in childhood.9-11 The extent of DDE depends on the intensity of the etiological factor, its duration and the period in which the factor was present during the formation of the crown. ${ }^{12}$

Teeth with DDE are more susceptible to caries, insofar as these teeth have retentive areas that make them more susceptible to the accumulation of bacterial plaque. Hypocalcification can lead to a more rapid progression of carious lesions. DDE can also affect the esthetics of the maxillary incisors, exerting a negative impact on social and psychological aspects. ${ }^{13}$ Thus, diagnosing and understanding the factors associated with DDE may contribute toward the prevention or minimization of adverse outcomes stemming from such defects. ${ }^{6,14}$

The present study was designed to evaluate associations between developmental defects of enamel (DDE) in the primary dentition and aspects related to mothers and preschoolers in the city of Diamantina, Brazil.

\section{Methodology}

A case-control study was conducted in the city of Diamantina, which is located in the northern portion of the state of Minas Gerais in southeastern Brazil. The study population included children from three to five years of age treated at the ten basic healthcare units in the city during immunization campaigns held in 2010. Diamantina has $90 \%$ vaccine coverage.

This investigation was carried out in two steps. A cross-sectional study was initially conducted to estimate the prevalence of DDE in preschool children aged three to five years. All teeth were evaluated by examiners submitted to a calibration procedure. In the second phase, a case-control study was conducted to identify risk factors associated with DDE in the primary dentition. The case group comprised 104 children with DDE and the control group was made up of 105 children without DDE, matched for gender and age. Children who did not cooperate during the exam and those with lip and/ or palate abnormalities ${ }^{15}$ or systemic problems, such as asthma ${ }^{16}$ and celiac disease, ${ }^{17}$ which are associated with DDE, were excluded from the study.

Data acquisition involved a clinical oral exam, anthropometric measures and a questionnaire administered in the form of an interview. The selection of the children for the case and control groups and the data collection were carried out on two separate days during the 2010 National Child Vaccination Campaign. A team of three researchers (an examiner and two assistants) was installed in each healthcare unit.

Prior to the fieldwork, the examiners underwent a calibration and training exercise for DDE diagnosis. Calibration was performed using images of different clinical situations, on two separate occasions, with a one-week interval between sessions. Kappa values were calculated. Minimum intraexaminer agreement was 0.81 and minimum interexaminer agreement was 0.80. A training exercise was then carried out, involving the clinical oral exam of children in the same age group as those participating in the main study.

The exam was performed with a disposable tongue depressor under natural light and gauze to clean the teeth. The child remained seated in a chair in front of the examiner and facing a window to make maximum use of natural light. The three types of DDE were assessed (diffuse opacity, demarcated opacity and enamel hypoplasia) and classified based on the criteria of the Modified Index of Development Defects of Enamel. ${ }^{4}$ Teeth with carious lesions that rendered the diagnosis of enamel defects impossible were excluded.

Anthropometric measures (weight and height) were used to assess nutritional status. The weight of the children was determined by placing them on a digital scale (Plenna, São Paulo, Brazil); food intake and excrement elimination were not taken into consideration. Height was determined by a stadiometer with a millimeter scale and two-meter limit (Welmy, Porto Alegre, Brazil), placed on a flat surface. Nutritional status was determined by comparing measurements with the reference standards stipulated by the American National Center for Health Statistics. ${ }^{18}$

Information on the birth of each child was ob- 
tained from the vaccination card. The children were classified based on birth weight using the criteria of the World Health Organization:

- very low birth weight (less than $1500 \mathrm{~g}$ ),

- low birth weight (less than $2500 \mathrm{~g}$ ) and

- normal birth weight (equal to or greater than $2500 \mathrm{~g}){ }^{19}$

Interviews were conducted with parents/guardians to gather information on socio-demographic aspects (monthly household income, mother's schooling, number of children in the family, and place of residence), mother's age at the birth of the child, child's age, gender and gestational age. Gestational age was classified as

- "full term" (37 or more weeks of gestation) and

- "premature birth" (less than 37 weeks of gestation). ${ }^{19}$

Data analysis was performed using the Statistical Package for the Social Sciences (SPSS for Windows, version 17.0, SPSS Inc., Chicago, USA) and included frequency distribution and association tests. Associations between DDE and the independent variables were determined using the chi-squared test. Poisson regression with robust variance was performed for the analysis of factors associated with DDE. The magnitude of each factor associated with the presence of DDE was determined using unadjusted prevalence ratios (PR), respective $95 \%$ confidence intervals $(\mathrm{CI})$ and p-values (Wald test). Explanatory variables with a $\mathrm{p}$-value $\leq 0.20$ for the bivariate analysis were incorporated into the model.

This study received approval from the Human Research Ethics Committee of the Universidade Federal dos Vales do Jequitinhonha e Mucuri, Brazil. Parents/guardians signed a statement of informed consent.

\section{Results}

None of the mothers refused to participate in either phase of the investigation. The prevalence of DDE in preschool children aged three to five years $(29.9 \%)$ was determined in the first phase of the study. The most common type was demarcated opacity (16.8\%), followed by diffuse opacity $(15.7 \%)$
Table 1 - Distribution of types of developmental defects of enamel in primary teeth according to the number of affected teeth per child in the case group $(n=104)$.

\begin{tabular}{|c|c|c|c|}
\hline \multirow[b]{2}{*}{$\begin{array}{l}\text { Number of } \\
\text { affected teeth }\end{array}$} & \multicolumn{3}{|c|}{ Developmental defects of enamel } \\
\hline & $\begin{array}{c}\text { Demarcated } \\
\text { opacity } \\
(n=56)^{*}\end{array}$ & $\begin{array}{l}\text { Diffuse opacity } \\
\qquad(\mathrm{n}=57)^{*}\end{array}$ & $\begin{array}{l}\text { Hypoplasia } \\
(\mathrm{n}=14)^{*}\end{array}$ \\
\hline None & $153(73.2)$ & $152(72.7)$ & 195 (93.3) \\
\hline One tooth & $31(14.8)$ & $30(14.4)$ & $5 \quad(2.4)$ \\
\hline Two teeth & $15 \quad(7.2)$ & $16 \quad(7.7)$ & $3(1.4)$ \\
\hline$\geq$ Three teeth & $10 \quad(4.8)$ & $11 \quad(5.3)$ & $6 \quad(2.9)$ \\
\hline
\end{tabular}

* Number of affected teeth per type of DDE in the case group.

and hypoplasia (4.2\%).

In the case-control study, the mean age of the children examined was 49.06 months (standard deviation $=6.68$ ). The most common type of DDE was diffuse opacity $(27.3 \%$; $\mathrm{n}=57)$, followed by demarcated opacity $(26.8 \% ; \mathrm{n}=56)$ and hypoplasia $(6.7 \%$; $\mathrm{n}=14)$. Table 1 shows the distribution of DDE according to the number of affected teeth per child. Table 2 shows the results of the associations between DDE and both socio-demographic and birthrelated variables.

The following maternal aspects and variables related to the child were associated significantly with the occurrence of DDE $(p<0.05)$ : mother's age at the birth of the child $(\mathrm{p}=0.012)$, breastfeeding $(\mathrm{p}=0.016)$ and monthly household income $(\mathrm{p}=0.030)$. In the unadjusted model, the mother's age at the birth of the child (PR: 1.47; 95\% CI: 1.1 to 1.9 ), absence of breastfeeding (PR: $1.67 ; 95 \% \mathrm{CI}$ : 1.2 to 2.3 ) and monthly household income less than twice the minimum wage (PR: 1.36 ; 95\% CI: 1.0 to $1.8)$ were significantly associated with DDE. In the adjusted multivariate regression model, the mother's age at the birth of the child (PR: 1.41; 95\% CI: 1.1 to 1.9 ) and absence of breastfeeding (PR: 1.57; $95 \%$ CI: 1.1 to 2.2 ) were significantly associated with a higher prevalence of DDE in the primary dentition, independently of monthly household income (Table $3)$.

\section{Discussion}

The present study examined associations between the occurrence of DDE in the primary dentition and 
Table 2 - Association between aspects related to child, mother and socio-demographic factors, and occurrence of developmental defects of enamel in the primary teeth of preschool children in Diamantina, Brazil (chi-squared test; $\mathrm{p}<0.05)$.

\begin{tabular}{|c|c|c|c|}
\hline & $\begin{array}{c}\text { Cases } \\
(n=104)\end{array}$ & $\begin{array}{l}\text { Controls } \\
(\mathrm{n}=105)\end{array}$ & $P$ \\
\hline \multicolumn{4}{|c|}{ Gestation, birth and breastfeeding } \\
\hline \multicolumn{4}{|c|}{ Age of mother at birth of child } \\
\hline - $\geq 24$ & 69 (44.2) & 87 (55.8) & \\
\hline$\cdot<24$ & $30(65.2)$ & $16(34.8)$ & 0.012 \\
\hline \multicolumn{4}{|l|}{ Gestation } \\
\hline - Full-term & 89 (48.9) & $93(51.1)$ & \\
\hline - Premature & $9(45.0)$ & $11(55.0)$ & 0.740 \\
\hline \multicolumn{4}{|l|}{ Birth weight } \\
\hline - $<2500 \mathrm{~g}$ & $9(39.1)$ & $14(60.9)$ & \\
\hline - $\geq 2500 \mathrm{~g}$ & $94(50.8)$ & 91 (49.2) & 0.291 \\
\hline \multicolumn{4}{|l|}{ Breastfeeding } \\
\hline - Yes & $92(47.7)$ & 101 (52.3) & \\
\hline - No & $12(80.0)$ & $3(20.0)$ & 0.016 \\
\hline \multicolumn{4}{|c|}{ Breastfeeding duration (months) } \\
\hline$\cdot \geq 6$ & $65(51.2)$ & $62(48.8)$ & \\
\hline$\bullet<6$ & $27(48.2)$ & $29(51.8)$ & 0.711 \\
\hline \multicolumn{4}{|c|}{ Current child variables } \\
\hline \multicolumn{4}{|l|}{ Nutritional diagnosis } \\
\hline - Ideal weight range & $84(48.0)$ & 91 (52.0) & \\
\hline - Overweight & $6(54.5)$ & $5(45.5)$ & \\
\hline - Malnourished & $12(60.0)$ & $8(40.0)$ & 0.562 \\
\hline \multicolumn{4}{|c|}{ Socio-demographic factors } \\
\hline \multicolumn{4}{|l|}{ Mother's schooling } \\
\hline - $\geq 8$ years & $45(48.4)$ & $48(51.6)$ & \\
\hline - $<8$ years & $59(50.9)$ & 57 (49.1) & 0.722 \\
\hline \multicolumn{4}{|l|}{ Household income } \\
\hline $\begin{array}{l}-\geq 2 \text { times the } \\
\text { minimum wage }\end{array}$ & $70(45.5)$ & $84(54.5)$ & \\
\hline $\begin{array}{l}-<2 \text { times the } \\
\text { minimum wage }\end{array}$ & 31 (63.3) & $18(36.7)$ & 0.030 \\
\hline
\end{tabular}

aspects related to mothers and preschoolers, particularly breastfeeding. Children who had not been breastfed had more enamel defects than those who had been breastfed. This result is in agreement with the findings of a previous case-control study carried out with Brazilian children, in which the lack of breastfeeding was associated with a 3.2-fold greater chance of DDE in the primary dentition. ${ }^{20}$

Human milk is a child's primary source of nutrients in the first months of life, including calcium. Calcium ions regulate cell activities, such as cell communication, signal transduction, enzyme activation and the polymerization of cytoskeletal proteins. ${ }^{21}$ Calcium also participates in the stage of amelogenesis in which there is loss of proteins from the matrix and input of calcium and potassium from the blood vessels that contribute to forming tooth enamel. ${ }^{22} \mathrm{~A}$ complete absence of calcium from one's diet is reported to result in hypomineralization of the enamel. ${ }^{23}$ This lends support to the hypothesis that the absence of breastfeeding deprives a child of calcium and causes DDE. However, this hypothesis does not appear to be valid for all teeth, insofar as the formation of the enamel matrix and calcification begin about the $15^{\text {th }}$ week of intrauterine life $;{ }^{24}$ however, this theory may be true for teeth that complete their formation in the post-uterine period. Moreover, since the tooth formation process may be altered by nutritional, vitamin and mineral deficiencies, ${ }^{2,9-11}$ the absence of breastfeeding may reduce the amount of nutrients during tooth formation, thereby leading to DDE.

No statistically significant association was found between premature birth and DDE. This finding may be explained by the small number of study children who had been born prematurely. Moreover, issues related to how this information associating premature birth and DDE was acquired could be the result of an interview format conditioned by the memory bias of the respondent. Previous studies carried out in different countries report that enamel defects are associated with premature birth. ${ }^{7-8,20}$ Children born prematurely may be affected by serious disorders related to calcium metabolism during the neonatal period, caused not only by prematurity itself, but also by numerous other complications encountered in these children. ${ }^{25}$

Maternal factors, such as age at the birth of the child, use of medications, infections and smoking during the prenatal period, have been associated with a higher prevalence of DDE. ${ }^{26}$ In the present study, the mother's age at the birth of the child was significantly associated with DDE. Children whose 


\begin{tabular}{|c|c|c|c|c|c|}
\hline \multirow{10}{*}{$\begin{array}{r}\text { Table } 3 \text { - Prevalence ratio } \\
\text { and confidence intervals } \\
\text { for associations between } \\
\text { developmental defects of enamel } \\
\text { and variables analyzed }(p<0.05) \text {. }\end{array}$} & Variable & $\begin{array}{c}\text { Unadjusted PR } \\
(95 \% \mathrm{Cl})\end{array}$ & $\mathrm{p}$ & $\begin{array}{c}\text { Adjusted PR } \\
(95 \% \mathrm{CI})\end{array}$ & $\mathrm{p}$ \\
\hline & \multicolumn{5}{|c|}{ Age of mother at birth of child (years) } \\
\hline & - $\geq 24$ & 1.0 & & 1.0 & \\
\hline & $\cdot<24$ & $1.47(1.1-1.9)$ & 0.006 & $1.41(1.1-1.9)$ & 0.018 \\
\hline & \multicolumn{5}{|c|}{ Breastfeeding } \\
\hline & - Yes & 1.0 & & 1.0 & \\
\hline & - No & $1.67(1.2-2.3)$ & 0.001 & $1.57(1.1-2.2)$ & 0.007 \\
\hline & \multicolumn{5}{|c|}{ Household income } \\
\hline & - $\geq 2$ times the minimum wage & 1.0 & & 1.0 & \\
\hline & - $<2$ times the minimum wage & $1.36(1.0-1.8)$ & 0.034 & $1.26(0.94-1.69)$ & 0.123 \\
\hline
\end{tabular}

mothers were under 24 years of age at the time of birth had a greater frequency of enamel defects. A mother's age is a well-known determinant of complications during pregnancy and delivery. ${ }^{27}$ Pregnancy in adolescence is associated with a higher risk of adverse outcomes, including low birth weight and premature birth. ${ }^{28}$ This hypothesis should be further investigated in longitudinal studies aimed at determining associations between complications during pregnancy and DDE in the primary dentition.

A mother's age at the birth of the child was also significantly associated with monthly household income $(\mathrm{p}<0.001)$ and schooling $(\mathrm{p}=0.035)$, and may therefore be used as a complementary datum in the evaluation of socioeconomic status. It is suggested that young mothers with a lower socioeconomic status are more susceptible to complications during pregnancy due to less access to healthcare services, lack of prenatal care or unsatisfactory assistance, resulting in premature birth and low birth weight, which are related to the etiology of DDE.

The association between breastfeeding and DDE found in the present study suggests the importance of breastfeeding in preventing these defects in the primary dentition. Breastfeeding contributes to reduced illness rates and complications in early life,

\section{References}

1. Suckling GW. Developmental defects of enamel - historical and present-day perspectives of their pathogenesis. Adv Dent Res. 1989 Sep;3(2):87-94. and is related to the development of dental structures. ${ }^{20}$ Therefore, breastfeeding and the follow-up of growth and development in the initial years of life are strongly recommended in promoting both general and oral health, as well as preventing undesirable conditions in children. In regard to enamel defects, these measures should be combined with the identification of risk factors and conditions such as dental caries, to establish early control and minimization of problems resulting from DDE.

The common occurrence of premature birth, low birth weight, nutritional deficiencies and lack of breastfeeding in poor regions underscores the need for longitudinal studies addressing social and biological factors associated with DDE. ${ }^{20}$ The identification of these factors is important for the adoption of preventive measures against not only these defects but also other oral and systemic problems with common risk factors.

\section{Conclusion}

The prevalence of developmental defects of enamel in the primary dentition was higher among children who had not been breastfed and those whose mothers were under 24 years of age at the birth of the child.
2. Seow WK. Enamel hypoplasia in the primary dentition: a review. ASDC J Dent Child. 1991 Nov-Dec;58(6):441-52. 
3. Slayton RL, Warren JJ, Kanellis MJ, Levy SM, Islam M. Prevalence of enamel hypoplasia and isolated opacities in the primary dentition. Pediatr Dent. 2001 Jan-Feb;23(1):32-6.

4. A review of developmental defects of the enamel dental index (DDE Index). Commission on Oral Health, Research \& Epidemiology. Report of an FDI Working Group. Int Dent J. 1992 Dec;42(6):411-26.

5. Lunardelli SE, Peres MA. Prevalence and distribution of developmental enamel defects in the primary dentition of pre-school children. Braz Oral Res. 2005 Apr-Jun;19(2):144-9.

6. Targino AG, Rosenblatt A, Oliveira AF, Chaves AM, Santos VE. The relationship of enamel defects and caries: a cohort study. Oral Dis. 2011 May;17(4):420-6.

7. Corrêa-Faria P, Martins-Júnior PA, Vieira-Andrade RG, Oliveira-Ferreira F, Marques LS, Ramos-Jorge ML. Developmental defects of enamel in primary teeth: prevalence and associated factors. Int J Paediatr Dent. 2012 May 1. doi: 10.1111/j.1365-263X.2012.01241.x. Epud ahead of print.

8. Pinho JR, Lamy Filho F, Thomaz EB, Lamy ZC, Libério SA, Ferreira EB. Are low birth weight, intrauterine growth restriction, and preterm birth associated with enamel developmental defects?. Pediatr Dent. 2012 May-Jun;34(3):244-48.

9. Massoni AC, Chaves AM, Rosenblatt A, Sampaio FC, Oliveira AF. Prevalence of enamel defects related to pre-, peri and postnatal factors in a Brazilian population. Community Dent Health. 2009 Sep;26(3):143-9.

10. Takaoka LA, Goulart AL, Kopelman BI, Weiler RM. Enamel defects in the complete primary dentition of children born at term and preterm. Pediatr Dent. 2011 Mar-Apr;33(2):171-6.

11. Rugg-Gunn AJ, Al-Mohammadi SM, Butler TJ. Malnutrition and developmental defects of enamel in 2- to 6-year-old Saudi boys. Caries Res. 1998 May-Jun;32(3):181-92.

12. Regezi JA, Sciubba JJ. Oral Pathology. 3th ed. Rio de Janeiro: Guanabara Koogan; 2000. Chapter 16, Anomalies of the dentition; p. 405-25.

13. Vargas-Ferreira F, Ardenghi TM. Developmental enamel defects and their impact on child oral health-related quality of life. Braz Oral Res. 2011 Nov-Dec;25(6):531-7.

14. Carvalho JC, Silva EF, Gomes RR, Fonseca JA, Mestrinho HD. Impact of enamel defects on early caries development in preschool children. Caries Res. 2011 Sep;45(4):353-60.

15. Ruiz LA, Maya RR, D’Alpino PH, Atta MT, Syizero NR. Prevalence of enamel defects in permanent teeth of patients with complete cleft lip and palate. Cleft Palate Craniofac J. 2012 Jan 31. Epub ahead of print.

16. Widmer RP. Oral health of children with respiratory diseases. Paediatr Respir Rev. 2010 Dec;11(4):226-32.

17. Rashid M, Zarkadas M, Anca A, Limeback H. Oral manifestations of celiac disease: a clinical guide for dentists. J Mich Dent Assoc. 2011 Oct;93(10):42-6.

18. Hamill PVV, Drizd TA, Johnson CL, Reed RB, Roche AF, Moore WM. Physical growth: National Center for Healt statistics percentiles. Am J Clin Nutr. 1979 Mar;32(3):607-29.

19. WHO: recommended definitions, terminology and format for statistical tables related to the perinatal period and use of a new certificate for cause of perinatal deaths. Modifications recommended by FIGO as amended October 14, 1976. Acta Obstet Gynecol Scand. 1977 Jan;56(3):247-53.

20. Lunardelli SE, Peres MA. Breast-feeding and mother-child factors associated with developmental enamel defects in the primary teeth of Brazilian children. J Dent Child (Chic). 2006 May-Aug;73(2):70-8.

21. Posner AS, Perloff A, Diorio AF. Refinement of the hydroxyapatite structure. Acta Crystallogr. 1958 Apr;11(4):308-9.

22. Warshawsky H, Nanci A. Stereo electron microscopy of enamel crystallites. J Dent Res. 1982 Dec;Spec No:1504-14.

23. Bonucci E, Lozupone E, Silvestrini G, Favia A, Mocetti P. Morphological studies of hypomineralized enamel of rat pups on calcium-deficient, and of its changes after return to normal diet. Anat Rec. 1994 Aug;239(4):379-95.

24. Rythén M, Sabel N, Dietz W, Robertson A, Nóren JG. Chemical aspects on dental hard tissues in primary teeth from preterm infants. Eur J Oral Sci. 2010 Aug;118(4):389-95.

25. Seow WK. Effects of preterm birth on oral growth and development. Aust Dent J. 1997 Apr;42(2):85-91.

26. Velló MA, Martínez-Costa C, Catalá M, Fons J, Brines J, Guijarro-Martínez R. Prenatal and neonatal risk factors for the development of enamel defects in low birth weight children. Oral Dis. 2010 Apr;16(3):257-62.

27. Vieira CL, Coeli CM, Pinheiro RS, Brandão ER, Camargo Jr KR, Aguiar FP. Modifying effect of prenatal care on the association between young maternal age and adverse birth outcomes. J Pediatr Adolesc Gynecol. 2012 Jun;25(3):185-9.

28. Fraser AM, Brockert JE, Ward RH. Association of young maternal age with adverse reproductive outcomes. N Engl J Med. 1995 Apr 27;332(17):1113-7. 